\title{
THE NUMERICAL STUDY WITH DYNAMIC MESH ON THE POLLUTION CONTROL EFFECT OF OPERATING TABLE PROTECTED BY LAMINAR FLOW SCREEN
}

\author{
FAN JULI \\ College of Aerospace Engineering, Nanjing University of Aeronautics and Astronautics, 29 YuDao St. \\ Nanjing, 210016, China \\ fjl@nuaa.edu.cn \\ TIAN LU \\ College of Aerospace Engineering, Nanjing University of Aeronautics and Astronautics, 29 YuDao St. \\ Nanjing, 210016, China \\ 1227368268@qq.com \\ JIA XUDONG \\ College of Aerospace Engineering, Nanjing University of Aeronautics and Astronautics, 29 YuDao St. \\ Nanjing, 210016, China \\ Published 22 June 2016
}

\begin{abstract}
Transmission of airborne bacteria is the main factor causing surgical site infection (SSI). Horizontal laminar flow screen is a kind of new clean equipment, which can prevent SSI effectively. Numerical simulation is conducted on the pollution control effect of operating table protected by horizontal laminar flow screen. A three-dimensional model is established, discrete phase model (DPM) is used for calculation. Numerical simulation is carried out to evaluate the particle trajectories with the Lagrange approach, and the dynamic mesh is used. Air movement in the case with and without people's walking is analyzed. As a result, people's walking would not affect the distribution of pollutants at the key area of the operating table, the vertex caused by the walking person does little influence on flow field of the whole operating room and the influence area is about $0.24 \mathrm{~m}$ to $0.75 \mathrm{~m}$ around the walking person. The protective effect of pollutants with horizontal laminar flow screen for the key areas of operating table is excellent. This work provides references for the study on the depuration of operating room or other occasion.
\end{abstract}

Keywords: Operating room; horizontal laminar flow screen; dynamic mesh; numerical study; DPM.

\section{Introduction}

Transmission of airborne bacteria is the main factor causing surgical site infection (SSI) ${ }^{1}$, which is harmful to patients' health and even lives, and would cause great economic burden. Therefore, it's important to prevent SSI. The microorganism of SSI mainly comes from three aspects ${ }^{2-3}$ : persons, surgical instruments, wall and ground ${ }^{4-6}$. These are

This is an Open Access article published by World Scientific Publishing Company. It is distributed under the terms of the Creative Commons Attribution 3.0 (CC-BY) License. Further distribution of this work is permitted, provided the original work is properly cited. 
current main prevention methods: Disinfecting the person and the goods that directly or indirectly contacted with the patients, using the antibiotics to reduce the probability of the patient's infection, using the air clean technology $y^{7-8}$. However, the antibiotic has side effect to our human body and some antibiotics are very expensive, otherwise, researches ${ }^{9-}$ 11 about clean technology of operating room at present are mainly about air purification of the overall indoor ${ }^{12-14}$, while the pertinence of the prevention on local infection in surgical critical areas is not enough.

Laminar flow screen ${ }^{11}$ is a new kind of clean equipment, it can be placed near the operating table or equipment table ${ }^{15-17}$. Researches ${ }^{10,11}$ have shown that the horizontal laminar flow screen could disinfect and remove harmful gas and smokes into local aseptic area such as the surgical critical area at a certain speed with a certain distance, while, it could make the air of protecting area reach high cleanliness.

In this paper, numerical simulation ${ }^{18,19}$ is conducted on the pollution control effect of operating table protected by horizontal laminar flow screen ${ }^{20,21}$. A three-dimensional model $^{24-25}$ is established, discrete phase model (DPM) is used for calculation. Numerical simulation is carried out to evaluate the particle trajectories with the Lagrange approach $^{26-28}$, and the dynamic mesh is used. Air movement in the case with and without people's walking is analyzed.

\section{Calculation Model}

A three-dimensional calculation model that is shown as Fig. 1 was established for 1 st grade clean operating room. The size of the operating room is $5.9 \mathrm{~m} * 3 \mathrm{~m} * 7 \mathrm{~m}$. The air condition supplies air in the top and retrieves air on both sides. The size of the air supply outlet is $2.4 \mathrm{~m} * 2.6 \mathrm{~m}$ and the return air inlet is $4.4 \mathrm{~m} * 0.32 \mathrm{~m}$. The air supply temperature is $22^{\circ} \mathrm{C}$. There are five medical staff in the room and the body size of each one is $0.2 \mathrm{~m}^{*} 0.4 \mathrm{~m}^{*} 1.7 \mathrm{~m}$. Among them, there is a nurse walking at the right corner. The process that the nurse walking from one side of the operating table to the other side will be simulated. The size of the surgical critical area on the operating table is $0.3 \mathrm{~m} * 0.5 \mathrm{~m} * 0.2 \mathrm{~m}$. The distance from laminar flow screen to the operating table is $1.2 \mathrm{~m}$.

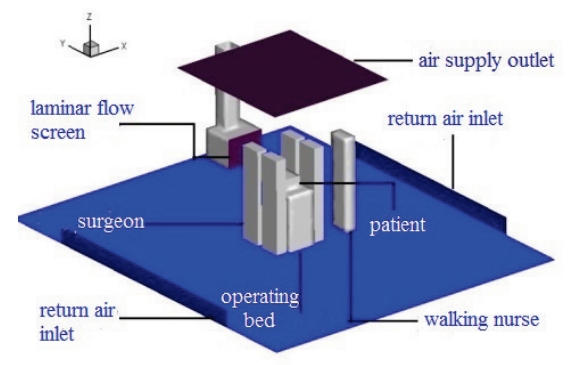

Fig. 1. The three-dimensional model of the operating room.

Studies ${ }^{29-30}$ have shown that bacteria in the operating room is mainly carried by the shed skin scrapings and the shed skin is the surface layer of the cuticle. So the bacteria 
particle diameter is set as 6 microns, the density is set as $1000 \mathrm{~kg} / \mathrm{m}^{3}$ and the weight is set as $9.04 * 10^{-13} \mathrm{~kg}$.

The quantity of bacteria carried by people is influenced by many factors. In accordance with the standard of Chinese people, the quantities of bacteria carried by different persons are set as follows: for each doctor or anesthetist, 200cfu on the upper body and 400cfu on the lower part of the body, and for each nurse, 150cfu on the upper body and 350cfu on the lower part of the body.

\section{Numerical Simulation}

Based on the three-dimensional model and conditions above, numerical simulation is conducted on the pollution control effect of operating table protected by horizontal laminar flow screen. Discrete phase model (DPM) is used for calculation. Numerical simulation is carried out to evaluate the particle trajectories ${ }^{31-33}$ with the Lagrange approach, and the dynamic mesh is used. Air movement in the case with and without people's walking is analyzed.

In DPM, different boundaries have different reactions to the particles: the surgical critical areas is set as "trap", outlet is set as "escape", inlet and the other boundary conditions of DPM are set as "reflect". Boundary conditions of this mode are set as follows: the type of inlet is set as velocity inlet, the type of the critical area is set as wall, the type of outlet is set as outflow, the type of particle source is set as mass flow inlet, the types of the boundaries are set as wall. The temperature is set as $300 \mathrm{~K}$. The speed of wind is $0.2 \mathrm{~m} / \mathrm{s}$. The mesh is generated by software of Gambit.

Elastic coefficient method and dynamic reconfiguration method are used in dynamic mesh. In the simulation the walking speed of person is set as $1 \mathrm{~m} / \mathrm{s}$ and the conditions of particles are set as follows: Except the walking nurse, other medical workers emit 800 particles each time step. The velocity of air supply is set as $0.2 \mathrm{~m} / \mathrm{s}$ and the time step is set as $0.01 \mathrm{~s}$. After three seconds, the nurse walks from one side of the operating table to the other side. In the simulation, particles emitted by the walking person are simplified to multiple points that are emitting particles at the same time.

\section{Results and Analysis}

\subsection{Analysis without person walking}

DPM is used to simulate the distribution of pollutants when there is no person walking. Simulation results of particle concentration at different heights are shown as Fig. 2 (z represents the height) It shows that the particle concentration of pollutant is the maximum at the ground $(\mathrm{z}=0 \mathrm{~m})$. This is because the influence of the air conditioner in the operating room, particles emitted by doctors are brought to the ground. It can be concluded that at the stationary state, most of the pollutants are close to the ground. And in this operating room model, particles on the ground can be expelled from the operating room through return air inlet. At the height of the operating table $(\mathrm{z}=1.2 \mathrm{~m})$, there are nearly no particles in the operation key area that is protected by a horizontal laminar flow screen. According 
to the simulation data, the number of particles sent out is 1884 , the number of particles escaped is 1883 and the number that trapped is 1 . This shows that $0.0053 \%$ of sent out particles are trapped. This indicates that horizontal laminar flow screen has excellent effect on the control of pollutants at the stationary state.

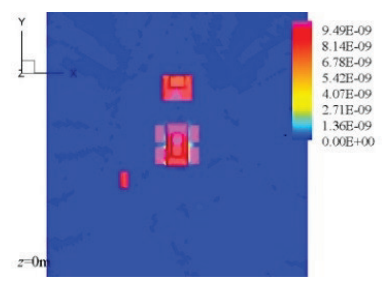

(a)

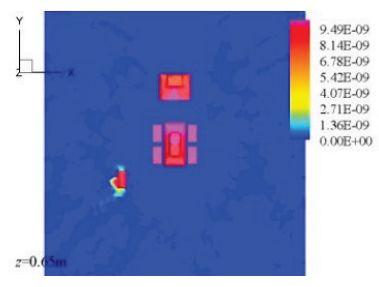

(b)

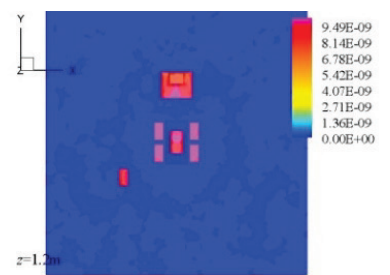

(c)

Fig. 2. The distribution of the particle concentration at different heights.

The flow field in the operating room at the stationary state is analyzed. The distribution of velocity vector is shown as Fig. 3. It shows that the existence of the nurse will affect the distribution of flow field, but to the whole flow field of the operating room, this influence could be neglected.

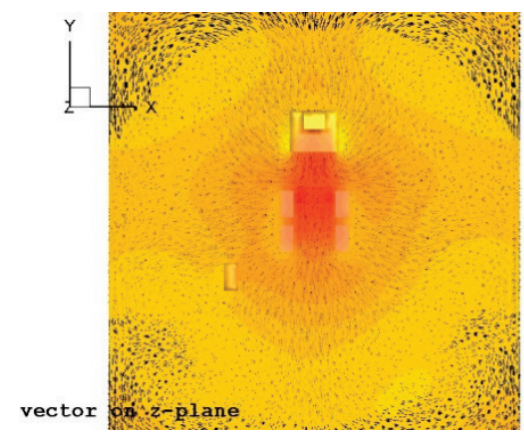

Fig. 3. The distribution of velocity vector in the operating room.

\subsection{Analysis with person walking}

When the movement time of ambulatory nurse is $1 \mathrm{~s}$, the distribution of particle concentration is shown as Fig. 4, and the simulation of flow field in the operating room is shown as Fig. 6(a). When the movement time of ambulatory nurse is $3 \mathrm{~s}$ (the nurse reaches the other side of the operating table), the corresponding results are shown as Figs. 5 and $6(b)$. 


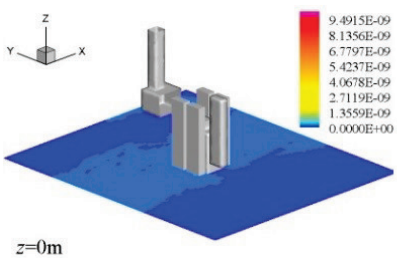

(a)

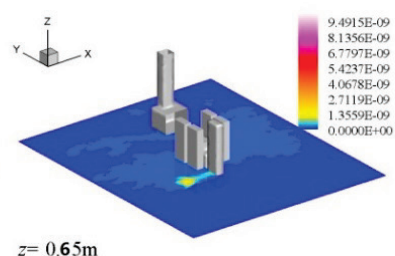

(b)

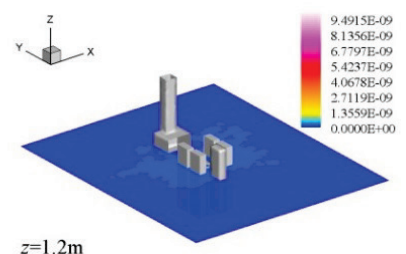

(c)

Fig. 4. The distribution of the particle concentration at different heights $(\mathrm{t}=1 \mathrm{~s})$.

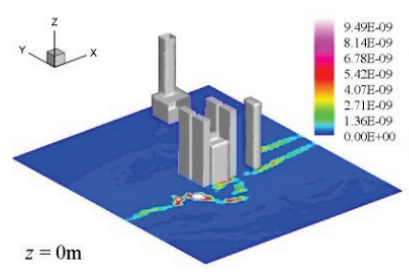

(a)

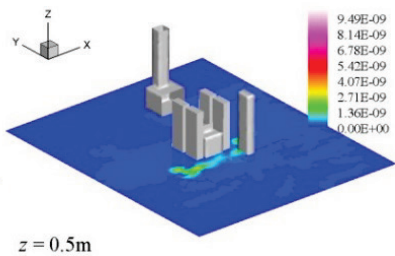

(b)

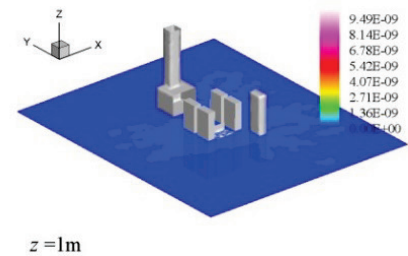

(c)

Fig. 5. The distribution of the particle concentration at different heights $(t=3 \mathrm{~s})$.

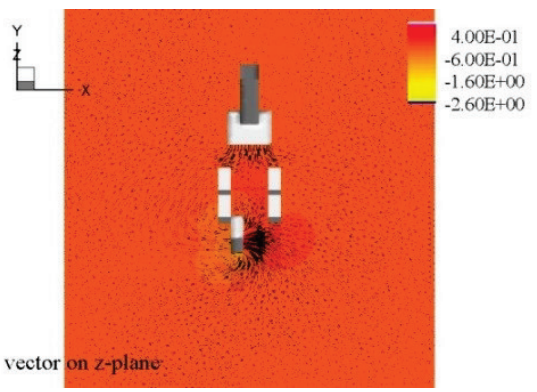

(a) $\mathrm{t}=1 \mathrm{~s}$

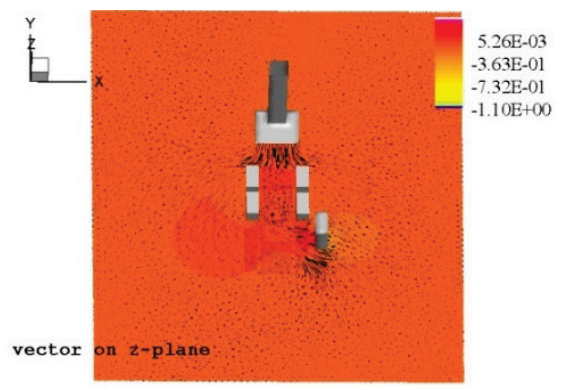

(b) $\mathrm{t}=3 \mathrm{~s}$

Fig. 6. The distribution of velocity vector in the operating room.

As a result, when $\mathrm{t}=1 \mathrm{~s}$, the number of particles emitted by person is 3768 , the escaped number is 3765 and the trapped number is 3 , which occupies $0.00076 \%$ of the total particles. When $\mathrm{t}=3 \mathrm{~s}$, the trapped number is 4 , which occupies $0.0011 \%$ of the total particles. From Figs. 4 and 6, it can be concluded that the particle concentration decreases with the height increases. The minimum concentration is zero at $\mathrm{z}=1.2 \mathrm{~m}$. This means that the clean effect of laminar flow screen is obvious. According to the analysis of the flow field, it can be concluded that the walking of person causes turbulence of the flow field and the influence area is about $0.24 \mathrm{~m}$ to $0.75 \mathrm{~m}$ around the walking person. There is a tiny 
vortex in front of the walking person. However, to the whole flow field in the operating room, it would cause little influence.

\section{Conclusions}

The simulation results of the distribution of the pollutant concentration show that when someone is walking, the area of the particle concentration field which would be influenced is mainly behind the person, and the pollutant concentration field at the key area of operating table have no obvious change. It can indicate that people's walking would not affect the distribution of pollutants at the key area of the operating table that is protected by the horizontal laminar flow screen.

According to the analysis results of flow field, it can indicate that the vertex caused by the walking person does little influence on flow field of the whole operating room and the influence area caused by the secondary air is about $0.24 \mathrm{~m}$ to $0.75 \mathrm{~m}$ around the walking person.

In conclusion, the protective effect of pollutants with horizontal laminar flow screen in operating room, especially for the key area of operating table, is excellent. This work provides references for the study on the depuration of operating room or other occasion.

\section{Acknowledgments}

Supported by the National Natural Science Foundation of China (51106074), China Postdoctoral Science Foundation and Special Foundation (2011M501227, 2012T50495).

\section{References}

1. Xiao-long Z, Zhi-jiang X, Chang-chun L, et al., Journal of Chongqing University (2008).

2. Ling Jihong, Tianjin University, Tianjin (2005).

3. Memarzadeh F, Manning A, ASHRAE journal. 45(2), 28(2003).

4. Takano Y, Maeda T, Takeno M, et al., IEEE Power and Energy Society General Meeting (2010).

5. Whitehouse A B, Lynn K A, Smith S W, US. (2010).

6. Ping-er Z, Xiao-ming H, Gui-juan J, et al., Chinese Journal of Nosocomiology (2010).

7. Linder P, Technical Reports. (1970).

8. Ram M, Gayley R I, Shaw G E, Journal of Aerosol Science. 20(3), 351 (1989).

9. Wei Xuemeng, Zhou Zudong, F Building Energy \& Environment. 20(2), 9(2001).

10. Zhang Yanguo, Xu Zhonglin, Zhang Yizhao, Building Science. 15(6), 6 (1999).

11. Fan Juli, Yang Xiaojing, Wang Sihan, et al., Transactions of Nanjing University of Aeronautics \& Astronautics. 30(3), 292(2013).

12. Scherrer M, Minimally Invasive Therapy \& Allied Technologies. 12(6), 293(2003).

13. Shu-jie H, Hong S, Machinery Design \& Manufacture (2009).

14. Hong L, Xiao-qiang J, Low Temperature \& Specialty Gase (2008).

15. Jia-ning Z, Xiao-shan Z, Journal of Harbin University of Commerce (2008).

16. Dao-he C, Pei-zhong L, Hong M, et al., Journal of Nursing (2006).

17. Zhi-ying M, Xiao-nuan Z, Yan Z, et al., Academic Journal of Pla Postgraduate Medical School (1997).

18. Song F, Journal of North China Electric Power University. (1996). 
19. Edwards J R, Kuznetsov A V, Mao D, et al., Chemical Engineering Science. 59(20), 4279 (2004).

20. Yu-ru H, Bu-xin X, Wei W, et al., Jiangsu Geology (2007).

21. Li-ying S, Yan L, Fluid Machinery. 38(3), 76 (2010).

22. Thompson D, Mundy J L, Proceedings of the International Conference on Robotics \& Automation. 208 (1987).

23. Treiber M, Advances in Pattern Recognition. 95 (2010).

24. Brooks R A, Artificial Intelligence. 17 (1981).

25. Lowe D G, The Kluwer international series in engineering and computer science (1984).

26. Zhang Rui, Tianjin University, Tianjin, China (2005).

27. Xia J, Leung D Y C, Atmospheric Environment. 35(33), 5779 (2001).

28. Ibsen C H, Helland E, Hjertager B H, et al., Powder Technology. 149(1), 29 (2004).

29. Xia Zhongliang, Hefei University of Technology, Hefei, China (2007).

30. Yan Wei, Building Energy \& Environment (2002).

31. Samuelsberg A, Hjertager B H, Aiche Journal. 42(6), 1536 (1996).

32. Mathiesen V, Solberg T, Arastoopour H, et al., Aiche Journal. 45(12), 2503 (1999).

33. Benyahia S, Arastoopour H, Knowlton T M, et al., Powder Technology. 112(1), 24 (2000). 